\title{
Ways and Methods for Comprehensively Raising Corporate Financing Level
}

\author{
Manping Weng, Xiaofang Wang* \\ Liming Vocational University, Quanzhou, Fujian, China \\ *Corresponding author: Xiaofang Wang \\ Email: weng28911985@163.com
}

Keywords: small and medium-sized enterprises; financing channels; integrity system

\begin{abstract}
The paper introduces how to develop the financing channels of small and medium-sized enterprises, vigorously develop the capital market, establish the credit system, as well as for small and medium enterprises how to improve the management level and economic benefits, enhance credit awareness, discusses the issues of establishing a regulatory and legal system, in order to solve the bottleneck of financing of small and medium-sized enterprises, and puts forward a series of channels for the financing of small and medium sized enterprises, so as to achieve a virtuous cycle of whole market economy. This paper mainly take Fujian Quanzhou as an example. The small and medium-sized enterprises in Quanzhou are widely distributed and are typical strong. In recent years, the financing of small and medium-sized enterprises plagued Quanzhou for the development of the market economy, so this paper hopes to help the financial reform of small and medium-sized enterprises in Quanzhou.
\end{abstract}

\section{Introduction}

Promoting the development of small and medium-sized enterprises is a long-term and arduous task. Financing difficulty has become a bottleneck for the development of SMEs in all regions. After a period of exploration, a relatively perfect SME financing system has been formed in some areas. Quanzhou small and medium-sized enterprises must constantly strive to overcome the weakness of market economic development and constantly improve enterprises financial management and improve the financial accounting standards and establish a good corporate credit for small and medium-sized enterprises,support with good quality for small and medium enterprises in Quanzhou to win broader financing channels

\section{Construction and Promotion of Good Faith System of Small and Medium-Sized Enterprises}

\subsection{Construction of the credit evaluation system of small and medium enterprises in Quanazhou}

Small and medium-sized enterprises in Quanzhou is the important guarantee for the sustained economic growth of Quanzhou. It is because the number of small and medium-sized enterprises in Quanzhou, which is mainly involved in various industries, is widely distributed that makes it become the core force to promote the development of state economy. At the same time, many small and medium-sized enterprises have greatly relieved the pressure of employment in Quanzhou anad played a key role in maintaining regional stability.

\subsection{A compound credit evaluation mode established by the government and market-oriented operation}

\subsubsection{A model of operation of government guidance}

A compound credit evaluation modal is established through government guidance, creating an honest and trustworthy business environment, and finding that businesses and individuals must provide credit data for a period of time to ensure reliable credit rating. 


\subsubsection{A model of free enterprise business with the development of free market}

It is a model with the development of free market, and the model depend on the market adjustment mechanism and economic law, the government is not allowed to intervene in the market. It is formed in the self management of continuous enterprise specific details of the operation of enterprise, the government's responsibility is to make the rules and regulations, and let the free market the operation. The interest orientation is the core of the enterprise's free operation model, which is represented by the United States.

\subsection{Establish the intermediary of in the evaluation the integrity of information of small and medium-sized enterprises in Quanzhou.}

Small and medium-sized enterprises in Quanzhou must solve the problem of asymmetric information, establish and improve the credit evaluation system of small and medium-sized enterprises in Quanzhou, must pass the credit agency investigation, collection and analysis of customer credit status and credit report issued in a timely manner to improve the integrity of Quanzhou SME information service channel.

\subsection{Establish the mechanism of incentive}

We must strengthen dishonesty is "far higher than" the "trust cost" .When the default cost less than material, money, time, and other benefits of other economic activities , market participants will deliberately choose breach of contract, and vice versa.

\subsection{Establish the improvement of the regulatory and legal bodies}

The lack of a benign operating mechanism and strict supervision and restriction mechanism to the small and medium-sized enterprises in Quanzhou is another bottleneck of the breach of promises in small and medium-sized enterprises, so it is very important for small businesses to strengthen their trust supervision, legal system and improve the integrity evaluation system of SEMS in Quanzhou.

Choose a compound model that is driven by the government and operates in the market. This is due to the small and medium-sized enterprise credit information is almost mastered by the government agencies and social services departments, the government administrative departments strengthen the supervision of small and medium-sized enterprises through the establishment of credit evaluation system of small and medium-sized enterprises combined with the understanding of the pubic, and then reduces the cost of financing.

\section{Construction of Financing Channels for Small and Medium -sized Enterprises}

\subsection{Establish and improve the law and policy system of financing for small and medium-sized enterprises}

In the development of small and medium-sized enterprises, although the government has taken certain measures, promulgate a series of policies and regulations to give support and help, but in reality, these polices and regulations obviously lags behind the need of the development of small and medium-sized enterprises in China, and there is no introduction of specific measures of small and medium-sized enterprises for the financing of SME and certain protection measures in bank financing and other financing channels. Therefore, it is necessary to strengthen the implementation of relevant protection clauses in the financing of relevant protection clauses in the financing of small and medium enterprises in China,

\subsection{Set up supporting measures for small and medium-sized enterprises' financing system}

\subsubsection{Effectively use private capital}

To solve the financial problems of small and medium-sized can't rely solely on commercial credit, but should be treated differently in specific reasons. Activating private capital is a good strategy for broadening financing channels. 


\subsubsection{Continuously expand various financing channels}

(1) Continue to expand the connotation of guarantee depends on the government-oriented guarantee

We should rely on the government guaranteed SME guarantee institutions, further improve the government funded property guarantee system, and absorb investment institutions, enterprises and private capital.

(2) Give full play to the Quanzhou small-credit company to promote its role

At the same time of carrying out subtstantive business, we should continue to build and improve the various small-credit company standardized operation and to encourage and support involvement of people capital, expand the operation scale, the expansion of the small loan in the small business credit bearing space.

(3) Further widening the equity financing channels

Make full use of the existing capital market to promote investment mutual participation in investment institutions, private equity funds and enterprises. In particular, it is necessary to open up the securities market for small and medium-sized enterprises, absorb a large amount of private capital and activate the hematopoietic mechanism .

(4) Actively develop new financial products and vigorously carry out personal entrusted loan business.

\subsection{Try to build a non-governmental cooperative financial institution.}

\subsubsection{Cooperative credit cooperatives}

The cooperative credit cooperatives are mainly rooted in the vast rural economies of the city. The funds of the cooperative credit cooperatives are raised by the members of the community, and they are also used in the members of the community to reflect the purpose of mutual assistance and cooperation. Some of the other developing countries on the international cooperation of financial institutions is old, and also provide experience of a more complete theory of our country credit cooperation. This theory develops in the international cooperative alliance and finally accepted voluntarily, including agency shares open for democracy; centralized management, a person a limited reward system; capital surplus; patrons returned to members.

\subsubsection{Private cooperative banks organizations}

The private cooperative banks organize private cooperation bank organizations, mainly based on the folk mutual trust cooperatives and form a joint stock system through voluntary organization economy, the private economy occupies the dominant position and has the right of control. These grass-roots cooperative banks and cooperatives can directly engage in the operation of the financial business and cooperatives can directly engage in the operation of financial business and hold shares in the regional cooperative banks.

In the management system,the management system of the German Cooperative Bank can be used for reference. System of German cooperative banks keep independents and synergy.

This multilevel joint cooperative economy has been proved by the practice of the western countries and has a strong vitality in the economic development. This kind of cooperative economy requires small and medium enterprises, individuals to participate in the effective economic competition, the core of it is to be owned by the members of the shares, independently managed by the members of the shares, and enjoyed the service by the members of the community.

\subsection{Establish the multilevel financing guarantee system for small and medium-sized enterprise}

To establish the multilevel financing guarantee system for small and medium-sized enterprises embodies certain practical significance, mainly manifested in two aspects: the one is to strengthen the village cooperation between banks and enterprises, expand the financing channels for SME in Quanzhou, the other is to provide small and medium-sized enterprises financing more choices. At present, the security institutions in Quanzhou have not yet made a large scale, and they are mature in system and operation, so that their guarantee function is greatly weakened. 
The development of small and medium enterprise guarantee institutions should be diversified, and their market orientation is different nature and different types of guarantee institutions. The first is the guarantee institutions of government, the guarantee organization should serve the financial market for the purpose of having certain policy guidelines, including not only guarantees but other investment should also have the function, the second is based on the purpose of the development of small and medium-sized enterprises, the nature of enterprise mutual guarantee institutions. In order to effectively solve the problems of financing difficulties of SME, develop guarantee institutions diversified better, need to do in a few points : the one is government funded and set up guarantee institutions, which purpose is not only to serve the financial market, in addition to the loan guarantee but also participate in the other business investment, but not for profit purposes, LED by the government; The second is to participate in the development by small and medium-sized enterprises, with the nature of mutual guarantee institutions, membership. The guarantee institutions for SWE voluntary combined, according to the proportion of investment in the principle of benefit distribution, with multiple input multiple income principle to serve in the small and medium-sized enterprises; The third is the commercial guarantee institutions. The purpose of the guarantee is to make a profit. The government is not allowed to limit its scope of operation. In order to solve the problem better of enterprise financing, the scope of its operation is wide.

\section{Acknowledgement}

Fujian Province Educational Science "Thirteenth Five-Year Plan" 2017 cross-strait Vocational Education Special Research Project

\section{References}

[1] Jiang Linjing, solution to the difficulty of financing for small and medium-sized enterprises, enterprise reform and management, 2011(2)22-29.

[2] Li Tanying, Wang Suzhen, the senior managers of SME of our country compensation incenticve of [J] enterprise economy, 2010(02)101-112.

[3] Xiao Jing, The coordination of deposit insurance system under construction--from the perspective of banking supervision analysis, legal system and social,2010(2)89-92.

[4] Wang Meng. Financing behavior dynamic game analysis of small and medium-sized enterprises, China trade based, 2010(5)123-139.

[5] Ding Mingli. Mall of financing in the small and medium-sized enterprises of our country modernization, 2011(26)112-119.

[6] Chen Hong. Promoting the development of SME in international experience, China market, 2007(31)451-456.

[7] Guo Tianyong. The financing of small and medium-sized enterprises comparison and the reference, International financial research. 2003. (11)15-22. 